\title{
Calcium, nutrient and food intake of Greek Orthodox Christian monks during a fasting and non-fasting week
}

\author{
Angeliki Papadaki, Constantine Vardavas, Christos Hatzis and Anthony Kafatos* \\ Preventive Medicine and Nutrition Unit, Department of Social Medicine, Medical School, University of Crete, \\ Greece PO Box 2208, Heraklion 710 03, Crete, Greece
}

Submitted 20 April 2007: Accepted 16 October 2007: First published online 20 December 2007

\begin{abstract}
Objective: To assess the Ca, nutrient and food intake of Greek Orthodox Christian monks during a vegetarian-type fasting week, compared with their normal diet. Design: Dietary data collection (using $7 \mathrm{~d}$ weighed food records), anthropometric and blood pressure measurements, as well as serum glucose and lipid analyses, were performed during Palm Sunday week (fasting) and the week following Pentecost Sunday (non-fasting). Mean daily nutrient and food (g/d) intakes were calculated from the food records.

Setting: The study took place in two monasteries in the Municipality of Heraklion, Crete.

Subjects: The study involved ten healthy monks aged 25-65 years, with BMI > $30 \mathrm{~kg} / \mathrm{m}^{2}$, who had been performing fasts for the last $24 \cdot 4$ (SD 10.4) years and lived in monasteries in Crete during April-June 2005.

Results: Nutrient and food intake profiles were more favourable during the fasting week, when participants had lower intakes of total and saturated fat and transfatty acids, and higher intakes of dietary fibre, Fe, folate, legumes and fish/ seafood. Ca intake was lower when participants fasted, whereas consumption of dairy products, meat and eggs increased significantly in the non-fasting week. Systolic blood pressure was significantly higher, whereas blood lipid levels were more favourable during the fasting week.

Conclusions: The periodic vegetarianism recommended by the Greek Orthodox Church contributes to the favourable profiles of several biomarkers of health among this sample of monks. The fasting rituals described are an important component of the traditional diet of Crete and should be emphasised in nutrition education programmes promoting this Mediterranean eating pattern.
\end{abstract}

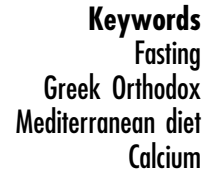

Calcium
The traditional Mediterranean diet of Crete is a dietary pattern that is promoted for its health benefits ${ }^{(1)}$. The Seven Countries Study was the first study to raise interest in this diet's health-promoting qualities, owing to the low overall mortality rates, low rates of chronic disease and increased longevity demonstrated by people living in Crete ${ }^{(2-5)}$. The excellent health of the population of Crete was attributed mainly to their diet, which was rich in plant foods and (mainly unrefined) cereals. In addition, the moderate intake of dairy products and the low consumption of animal foods gave a low intake of saturated fat, whereas the use of olive oil as the main source of fat in the diet provided an abundant intake of healthpromoting antioxidants and plant sterols ${ }^{(6)}$. The lifestyle of the population of Crete was also characterised by moderate to vigorous daily physical activity ${ }^{(2)}$. Despite their rich dietary heritage, the dietary habits of the Cretan population have been deteriorating over the last four decades and have started to resemble a more 'Western' eating pattern, characterised by increased consumption of animal products and reduced intake of cereals, fruits, legumes and vegetables ${ }^{(5)}$.

One of the main characteristics of the Mediterranean diet of Crete and Greece, which was ignored by the original investigators of the Seven Countries Study ${ }^{(7)}$, was the periodic fasting practised by members of the Greek Orthodox Church. In recent years, much interest has focused on this special practice that is retained and is characteristic of the Mediterranean diet of Crete and its suggested beneficial effect on dietary habits and health ${ }^{(8-11)}$. According to the Greek Orthodox Church dietary recommendations, fasting occurs at three major periods during the year: Christmas ( $50 \mathrm{~d}$ ); Easter Lent ( $40 \mathrm{~d}$ ); and the Assumption ( $15 \mathrm{~d}$ ), in addition to almost every Wednesday and Friday. During these periods, which total approximately $180-200 \mathrm{~d}$ annually, the consumption of foods of animal origin, dairy products and olive oil is restricted, fish intake is allowed only during 
Christmas and intake of seafood and snails is always allowed ${ }^{(9)}$. Snails, in particular, are often consumed in Greece (and especially Crete), mainly in casseroles with tomatoes and wheat or vegetables but also fried in olive oil and vinegar. They are consumed mainly during spring/summer months, irrespective of fasting. However, they are a good source of protein, $\mathrm{Ca}$ and $\alpha$-linolenic acid during fasting, whereas they are low in total and saturated fat $^{(12)}$. Consequently, adherence to this fasting ritual results in the periodic consumption of a vegetarian diet $^{(13)}$, which characterises the reported Mediterranean diet of Crete and Greece ${ }^{(5,14)}$.

The role of $\mathrm{Ca}$ in the regulation of cellular processes determining health and well-being is well recognised ${ }^{(15)}$. Adequate $\mathrm{Ca}$ intake is critical to the acquisition of ideal peak bone mass and the maintenance of bone mineral density in adults ${ }^{(16-18)}$. Milk and dairy products are the main food sources of $\mathrm{Ca}$, in addition to providing this mineral in a form readily absorbable by the body, whereas the bioavailability of $\mathrm{Ca}$ from plant foods is questionable ${ }^{(15,19,20)}$. A growing body of evidence, however, supports the beneficial effects of fruits and vegetables on bone health ${ }^{(21)}$. Inulin, for example, a substance abundant in certain plants such as artichokes, has been reported to increase $\mathrm{Ca}$ absorption $^{(22)}$, whereas $\mathrm{Ca}$ absorption from low-oxalate vegetables, such as kale and broccoli, appears to be excellent ${ }^{(23)}$. In the traditional diet of Crete, dairy products are the principal source of dietary $\mathrm{Ca}$, in addition to legumes, vegetables, nuts and small fish. Since the fasting rituals of the Greek Orthodox Church involve the periodic restriction of dairy products, their impact on dietary $\mathrm{Ca}$ intake is as yet unclear.

The aim of the present study was to add to the earlier literature examining the impact of the Greek Orthodox Christian Church's dietary recommendations on the food intake and nutrient composition of diets of adherents to this Church's fasting rituals, and to assess the adequacy of such a diet in $\mathrm{Ca}$. To our knowledge, this is the first specific study evaluating the intake of this important mineral in the Mediterranean diet and, in particular, its intake during a dietary fasting period associated with a religious practice. Although $\mathrm{Ca}$ intake during fasting is expected to be relatively low due to the restriction of dairy products in the diet, we hypothesised that, overall, dietary habits and nutrient and non-nutrient intakes would be more favourable during a fasting compared with a non-fasting period.

\section{Materials and methods}

\section{Participants}

A total of eleven Greek Orthodox Christian monks from the area of Heraklion, Crete participated in the present study. These men were faithful fasters, who adhered to all the Orthodox Christian Church fasting recommendations ${ }^{(9)}$. To recruit such participants, two monasteries in the Municipality of Heraklion were contacted and all monks were orally informed about the study. Eligibility criteria included males aged 25-65 years and in good health, as determined by medical history and physical examination. Participants were ineligible if they had a history of cardiovascular, liver or renal disease; cancer; gastrointestinal disorders; diabetes; lactose malabsorption or intolerance. In addition, we did not include participants taking medication known to negatively influence Ca bioavailability (e.g. anticonvulsants, glucocorticoids), or smokers. During the study, participants were required to consume their usual diets. The monasteries did not have a central feeding system and every participant was free to prepare and consume meals of their choice. Those who met the study criteria, were willing, and agreed to participate, signed an informed consent form. Participation was voluntary and anonymity was ensured. The study was conducted from April 2005 to June 2005 and approval was obtained from the Medical School Ethics Committee of the University of Crete.

\section{Study design}

Two sets of examinations were scheduled to cover one Greek Orthodox Church fasting week (Palm Sunday week) and one non-fasting week (week following Pentecost Sunday). All measurements were performed on Mondays, one day following the end of each examination period, between 08.00 and 10.00 hours, and included the collection of fasting blood and $24 \mathrm{~h}$ urine samples (biochemical analysis), anthropometric and blood pressure measurements, dietary intake and collection of duplicate food portions for chemical analyses, and bone mineral density measurements. The present paper reports data from dietary, anthropometric and blood pressure measurements, as well as blood glucose and lipid analyses. Results not reported here will be reported in a forthcoming publication.

\section{Antbropometric measurements}

All anthropometric measurements were performed by the same researcher. Body weight was measured at both assessment weeks (fasting and non-fasting) with a portable digital scale (model 770; Seca, Hamburg, Germany) with an accuracy of $\pm 100 \mathrm{~g}$, with participants in light clothing and without shoes. Standing height was measured once with a stadiometer (model 225; Seca), measuring to the nearest $0 \cdot 1 \mathrm{~cm}$, on participants without shoes, with shoulders relaxed, with arms hanging freely and with heels adducted. BMI was calculated as weight $(\mathrm{kg})$ divided by height squared $\left(\mathrm{m}^{2}\right)$.

\section{Blood pressure measurements}

Arterial blood pressure measurements were performed during both assessment weeks with a mercury sphygmomanometer (Focal FC-110, Tokyo, Japan), with 
participants resting for $10 \mathrm{~min}$ before measurements. The width of the cuff was placed at the highest possible part of the right arm, covering $50-75 \%$ of the area. The measurement was taken three times, with a $2-3 \mathrm{~min}$ interval between each reading. The mercury was allowed to fall $2 \mathrm{~mm} / \mathrm{s}$. Final readings of systolic and diastolic blood pressure were taken as the mean values of the second and third measurements.

\section{Blood samples}

Blood samples were drawn in the morning, after a $12 \mathrm{~h}$ overnight fast, one day following the end of each examination period. Blood samples were drawn into EDTA sample tubes (K2E, Vacutainer 368861; BD, Plymouth, UK) without stasis by venepuncture (antecubital fossa) and the serum was separated by centrifugation at $1100 \mathrm{~g}$ for $10 \mathrm{~min}$ at $4^{\circ} \mathrm{C}(\mathrm{Z} 400 \mathrm{~K}, \mathrm{rpm} 4000$; Hermle, Wehingen, Germany) and frozen at $-80^{\circ} \mathrm{C}$ until assayed. Serum total cholesterol (TC), TAG and blood glucose (CIBA Corning kits; Gilford Systems, Oberlin, OH, USA) were determined on the day of collection. HDL-cholesterol (HDL-C) was determined after apoB-containing lipoproteins were precipitated by the dextran sulphate-manganese method $^{(24)}$. LDL-cholesterol (LDL-C) was estimated using the Friedewald formula ${ }^{(25)}$.

All clinical chemistry measurements were performed in a Gilford-400 autoanalyser (Corning Laboratory Sciences Co., Oberlin, OH, USA). Besides the internal quality control, the laboratory of the Department of Social Medicine participates in the Wellcome Diagnostic Laboratory external quality-control programme. The serum TC concentrations of our laboratory were within the prescribed two standard deviations of the mean Wellcome values during the period of the study.

\section{Dietary data}

All participants were provided with food scales and record forms, in order to record their food and liquid intake for seven consecutive days. Participants were required to weigh all foods and beverages consumed over the fasting and non-fasting weeks of measurements and to provide cooking methods and recipes for any composite meals. The food scales (model 2006; Salter, Kent, UK) had a maximum weight capacity of $1 \mathrm{~kg}$ and precision of $\pm 1 \mathrm{~g}$. Detailed written and oral instructions for completion of the $7 \mathrm{~d}$ weighed food records were provided and participants were encouraged to contact the researchers if they had any questions regarding this procedure. A date for commencement of diary completion was set and completed diaries were returned during a meeting with the researchers, following the last diary entry date.

Dietary records were checked for completeness on-site to clarify any queries (e.g. unknown food items or food servings). To avoid coding errors, data were computer entered by the same researcher, using a comprehensive
Greek national food composition database that is currently under construction and includes some chemically analysed Greek-origin foods. In the case when a consumed food item was not included in the database, participants were either asked to provide specific recipes or food brand names, or values from an item of similar nutrient content were used. The food database Greek Diet, used to calculate dietary intakes, was initially created in 1990 by the Preventive Medicine and Nutrition Clinic of the University of Crete and was upgraded in 1998 using the USDA Nutrient Database for Standard Reference release 11 (USDA Agricultural Research Service, Washington, DC, USA). A description of the database has been published in detail elsewhere ${ }^{(11,26)}$.

The food items and recipes were categorised into sixteen food groups: bread; cereals; potatoes; milk and yoghurt; cheese; eggs; meat, poultry and meat products; fish and seafood; legumes (including peas); snails; fruits, nuts and seeds; vegetables; alcoholic drinks; fats and oils; sugar and sugar products; and pastries. Mean daily food $(\mathrm{g} / \mathrm{d})$, nutrient and micronutrient intakes were calculated from the food records.

\section{Statistical analysis}

All analyses were performed using the Statistical Package for the Social Sciences statistical software package (SPSS for Windows) release $11 \cdot 5$ (SPSS Inc., Chicago, IL, USA) and significance was defined as $P<0.05$ (two-sided). Mean intakes (with standard deviations) of energy, macro- and micronutrients, as well as foods, were calculated from the $7 \mathrm{~d}$ weighed food records. Comparisons of anthropometric and blood pressure measurements, fasting serum glucose and lipids, and dietary intakes during the two assessment weeks (fasting and nonfasting) were performed with the use of the Wilcoxon signed ranks test and the paired-samples $t$ test for nonnormal and normally distributed variables, respectively.

\section{Results}

Of the eleven monks who agreed to take part in the study, one was not available during the examinations performed in the non-fasting week, resulting in complete data (from both fasting and non-fasting weeks) from ten participants. Participants' age ranged from 25 to 65 years, with a mean age of $37 \cdot 5$ (SD $12 \cdot 3)$ years and they had been involved in fasting, according to the tradition, for an average of $24 \cdot 4$ (SD 10.4) years prior to the study.

\section{Comparisons of antbropometric, blood pressure and biochemical measurements}

Table 1 depicts the anthropometric, blood pressure and biochemical analysis results. Body weight and BMI were slightly higher during the non-fasting week, as opposed 
Table 1 Anthropometric, blood pressure, fasting serum glucose and blood lipid measurements in Greek Orthodox Christian monks during a fasting and a non-fasting week

\begin{tabular}{|c|c|c|c|c|c|}
\hline & \multicolumn{2}{|c|}{ Fasting week ( $n$ 10) } & \multicolumn{2}{|c|}{ Non-fasting week ( $n$ 10) } & \multirow[b]{2}{*}{$P$} \\
\hline & Mean & SD & Mean & SD & \\
\hline Body weight (kg) & $89 \cdot 3$ & $10 \cdot 8$ & $90 \cdot 9$ & $11 \cdot 3$ & $0 \cdot 059^{*}$ \\
\hline BMI $\left(\mathrm{kg} / \mathrm{m}^{2}\right)$ & $30 \cdot 8$ & $4 \cdot 3$ & $31 \cdot 3$ & $4 \cdot 6$ & $0.059^{*}$ \\
\hline Systolic blood pressure $(\mathrm{mmHg})$ & 124 & $12 \cdot 5$ & 116 & $13 \cdot 9$ & $0.012 t$ \\
\hline Diastolic blood pressure $(\mathrm{mmHg})$ & 78 & $6 \cdot 6$ & 77 & $7 \cdot 1$ & $0.654 t$ \\
\hline Serum glucose $(\mathrm{mg} / \mathrm{dl})$ & $91 \cdot 1$ & $7 \cdot 9$ & $94 \cdot 2$ & $11 \cdot 2$ & $0.253+$ \\
\hline Serum TC $(\mathrm{mg} / \mathrm{dl})$ & 161 & $29 \cdot 6$ & 196 & $43 \cdot \overline{1}$ & $0.005^{*}$ \\
\hline Serum LDL-C (mg/dl) & 91.9 & $27 \cdot 0$ & $134 \cdot 0$ & $38 \cdot 4$ & $0.005^{*}$ \\
\hline Serum HDL-C (mg/dl) & $39 \cdot 2$ & $8 \cdot 1$ & $41 \cdot 2$ & $9 \cdot 2$ & $0 \cdot 193+$ \\
\hline TC:HDL-C & $4 \cdot \overline{3}$ & $1 \cdot 0$ & $4 . \overline{9}$ & $1 \cdot 2$ & $0.005^{*}$ \\
\hline Serum TAG (mg/dl) & $149 \cdot 0$ & $73 \cdot 8$ & $99 \cdot 1$ & $43 \cdot 6$ & $0 \cdot 017^{*}$ \\
\hline
\end{tabular}

TC, total cholesterol; LDL-C, LDL-cholesterol; HDL-C, HDL-cholesterol.

*Levels of significance were assessed with the use of the Wilcoxon signed ranks test.

tLevels of significance were assessed with the use of the paired-samples $t$ test.

to the fasting week, and slightly above ideal, although all monks were apparently healthy. Interestingly, systolic and diastolic blood pressure measurements were lower during the non-fasting week, but only systolic blood pressure reached statistical significance. In contrast, TC and LDL-C levels were significantly increased at the end of the non-fasting week, probably reflecting the higher intake of animal foods (see Table 4), whereas the increase (albeit not significant) in HDL-C levels for the same week probably reflected the increased TC levels and perhaps the absence of olive oil during the fasting week in the diets of many of the participants studied. The ratio of TC:HDL-C, a better predictor of CHD risk status than TC levels ${ }^{(27)}$, was also significantly lower during the fasting week, suggesting the potential contribution of the Greek Orthodox fasting rituals to favourable blood lipid profiles.

\section{Comparisons of nutrient intakes}

Comparisons of energy, macro- and micronutrient intakes for the two assessment weeks are presented in Table 2. Several favourable patterns emerged during the fasting week, when intakes of total and saturated fat, trans-fatty acids and dietary cholesterol were lower compared with the non-fasting week, and intakes of dietary fibre and folate were higher. Despite meat and meat products being an important source of $\mathrm{Fe}$ in the diet, intake of this mineral was significantly higher when participants fasted. This might have resulted from the participants' increased intake of legumes, shellfish, snails and nuts, all good sources of $\mathrm{Fe}$ in the diet, during the fasting week. In contrast, dietary intake of Ca was significantly lower during the fasting week than the non-fasting week, most probably reflecting the absence of dairy products in participants' diets during that period. Intake of protein was also significantly higher when participants followed their non-fasting diets, possibly due to the non-prohibited consumption of animal protein-rich foods (e.g. meat, dairy products) at non-fasting periods.
Significant favourable differences were also observed when macronutrient intake was expressed as a percentage of the daily energy intake (Table 3). Thus, participants had lower intakes of total and saturated fat, as well as trans-fatty acids, lower intakes of protein and higher intakes of total carbohydrates when they fasted.

\section{Comparisons of food consumption}

Table 4 presents the comparison of daily consumption of selected foods during the two assessment weeks. As expected, consumption of dairy products, eggs, as well as meat and meat products was significantly higher when participants did not fast. In contrast, the consumption of legumes and fish and seafood was significantly higher during the non-fasting week. An interesting finding is that although changes in total fruit and vegetable consumption did not reach statistical significance, daily intake of this food group was reduced by more than one serving $(104 \mathrm{~g})^{(28)}$ during the non-fasting week, which can be considered of clinical significance according to current recommendations regarding fruit and vegetable consumption ${ }^{(29)}$.

\section{Discussion}

Overall, the findings of the present study indicate a more favourable dietary profile during a fasting week for monks who are devout Greek Orthodox adherents, when a periodic vegetarian-type of diet is followed as compared with these monks' normal diets. In addition, this healthy eating pattern was reflected in favourable blood lipid levels, suggesting the potential benefits of the Greek Orthodox Church fasting rituals regarding chronic disease prevention.

The present study contributes to obtaining an overall picture of the fasting diet recommended by the Greek Orthodox Church and the food habits that may be responsible for providing nutritional benefits. Our results agree with an earlier study investigating the eating habits 
Table 2 Estimation of daily energy and nutrient intake in Greek Orthodox Christian monks during a fasting and a non-fasting week, based on $7 \mathrm{~d}$ weighed food records

\begin{tabular}{|c|c|c|c|c|c|}
\hline \multirow[b]{2}{*}{ Energy or nutrient } & \multicolumn{2}{|c|}{ Fasting week (n 10) } & \multicolumn{2}{|c|}{ Non-fasting week ( $n$ 10) } & \multirow[b]{2}{*}{$P$} \\
\hline & Mean & SD & Mean & SD & \\
\hline Energy (MJ) & $8 \cdot 49$ & $2 \cdot 32$ & $9 \cdot 37$ & 1.94 & $0 \cdot 286+$ \\
\hline Energy (kcal) & 2030 & 554 & 2240 & 464 & \\
\hline Protein $(\mathrm{g})$ & $60 \cdot 8$ & $19 \cdot 0$ & $76 \cdot 8$ & $17 \cdot 0$ & $0 \cdot 028^{*}$ \\
\hline Total fat $(\mathrm{g})$ & $86 \cdot 6$ & $25 \cdot 1$ & $120 \cdot 0$ & $19 \cdot 7$ & $0 \cdot 013^{*}$ \\
\hline SFA (g) & $13 \cdot 9$ & $4 \cdot 2$ & $33 \cdot 5$ & $7 \cdot 9$ & $0.005^{\star}$ \\
\hline MUFA (g) & $50 \cdot 4$ & $16 \cdot 5$ & $57 \cdot 2$ & $10 \cdot 6$ & $0 \cdot 200 t$ \\
\hline Total cis-MUFA (g) & $43 \cdot 9$ & $17 \cdot 6$ & $55 \cdot 7$ & $10 \cdot 7$ & $0.059^{*}$ \\
\hline PUFA (g) & $14 \cdot 2$ & $6 \cdot 2$ & $13 \cdot 8$ & $5 \cdot 3$ & $0 \cdot 878^{*}$ \\
\hline Total cis-PUFA (g) & $11 \cdot 0$ & $5 \cdot 6$ & $12 \cdot 7$ & $5 \cdot 1$ & $0 \cdot 386^{*}$ \\
\hline Total cis-unsaturated fatty acids (g) & $54 \cdot 2$ & $20 \cdot 7$ & $68 \cdot 4$ & $14 \cdot 2$ & $0 \cdot 139^{*}$ \\
\hline Trans-fatty acids (g) & 0.36 & 0.45 & 1.55 & 0.54 & $0.005^{*}$ \\
\hline$n-6$ fatty acids $(\mathrm{g})$ & $9 \cdot 59$ & $5 \cdot 81$ & $12 \cdot 30$ & $4 \cdot 74$ & $0 \cdot 241^{*}$ \\
\hline$n-3$ fatty acids $(\mathrm{g})$ & 0.75 & 0.34 & 0.90 & 0.39 & $0.283^{*}$ \\
\hline $12: 0+14: 0+16: 0(\mathrm{~g})$ & $8 \cdot 53$ & 3.07 & $22 \cdot 20$ & $5 \cdot 47$ & $<0.001 \dagger$ \\
\hline Total carbohydrates (g) & 252 & $97 \cdot 0$ & 208 & $82 \cdot 7$ & $0 \cdot 169^{*}$ \\
\hline Total sugars $(\mathrm{g})$ & 53.9 & $17 \cdot 7$ & 59.9 & $32 \cdot 0$ & $0.421 t$ \\
\hline Dietary fibre $(\mathrm{g})$ & $27 \cdot 7$ & $8 \cdot 0$ & $13 \cdot 8$ & $2 \cdot 8$ & $<0.001 t$ \\
\hline Alcohol $(\mathrm{g})$ & $6 \cdot 33$ & $11 \cdot 20$ & $6 \cdot 12$ & $7 \cdot 59$ & $0 \cdot 407^{\star}$ \\
\hline Cholesterol (mg) & 135 & $65 \cdot 1$ & 310 & $80 \cdot 4$ & $0.005^{\star}$ \\
\hline Phytosterols (mg) & 154 & $62 \cdot 3$ & 152 & $38 \cdot 1$ & $0.916+$ \\
\hline $\mathrm{Ca}(\mathrm{mg})$ & 429 & 96 & 702 & 350 & $0.022^{*}$ \\
\hline $\mathrm{Fe}(\mathrm{mg})$ & $17 \cdot 7$ & $6 \cdot 4$ & $11 \cdot 8$ & 2.5 & $0.008+$ \\
\hline $\mathrm{K}(\mathrm{mg})$ & 3120 & 744 & 2890 & 692 & $0 \cdot 285^{\star}$ \\
\hline $\mathrm{Na}(\mathrm{mg})$ & 1640 & 729 & 1790 & 709 & $0 \cdot 646^{*}$ \\
\hline$M g(m g)$ & 366 & 152 & 237 & 54 & $0.009^{*}$ \\
\hline$P(\mathrm{mg})$ & 1080 & 442 & 1130 & 292 & $0 \cdot 721^{*}$ \\
\hline $\mathrm{Zn}(\mathrm{mg})$ & $7 \cdot 58$ & $3 \cdot 47$ & 8.59 & $2 \cdot 17$ & $0.386^{*}$ \\
\hline Folate (mg) & 326 & 122 & 160 & 30 & $0.005^{\star}$ \\
\hline Vitamin A (RE) & 769 & 561 & 755 & 456 & $0 \cdot 721^{*}$ \\
\hline Vitamin A (IU) & 7270 & 5500 & 5500 & 4910 & $0.508^{*}$ \\
\hline Vitamin E (mg) & $11 \cdot 30$ & $4 \cdot 16$ & $9 \cdot 36$ & $2 \cdot 19$ & $0 \cdot 160 t$ \\
\hline Vitamin C (mg) & 113 & $39 \cdot 2$ & 103 & $40 \cdot 1$ & $0.285 t$ \\
\hline Thiamin (mg) & $1 \cdot 49$ & 0.63 & $2 \cdot 08$ & $1 \cdot 61$ & $0 \cdot 386^{*}$ \\
\hline Riboflavin (mg) & $1 \cdot 08$ & 0.43 & $2 \cdot 33$ & $1 \cdot 42$ & $0.022^{*}$ \\
\hline $\operatorname{Niacin}(\mathrm{mg})$ & $17 \cdot 3$ & $6 \cdot 0$ & $19 \cdot 0$ & $6 \cdot 2$ & $0.508^{*}$ \\
\hline Pantothenic acid (mg) & 3.04 & 0.85 & $4 \cdot 19$ & 0.99 & $0.028^{*}$ \\
\hline Vitamin $B_{6}(\mathrm{mg})$ & $1 \cdot 45$ & 0.42 & $1 \cdot 84$ & 0.51 & $0.074^{\star}$ \\
\hline Vitamin $B_{12}(\mu \mathrm{g})$ & 3.66 & $2 \cdot 13$ & $4 \cdot 42$ & $3 \cdot 11$ & $0 \cdot 721^{*}$ \\
\hline
\end{tabular}

$\mathrm{RE}$, retinol equivalents.

*Levels of significance were assessed with the use of the Wilcoxon signed ranks test.

tLevels of significance were assessed with the use of the paired-samples $t$ test.

Table 3 Estimation of daily macronutrient intake, expressed as percentage of daily energy intake, in Greek Orthodox Christian monks during a fasting and a non-fasting week, based on $7 \mathrm{~d}$ weighed food records

\begin{tabular}{|c|c|c|c|c|c|}
\hline \multirow[b]{2}{*}{ Macronutrient } & \multicolumn{2}{|c|}{ Fasting week ( $n$ 10) } & \multicolumn{2}{|c|}{ Non-fasting week (n 10) } & \multirow[b]{2}{*}{$P^{*}$} \\
\hline & Mean & SD & Mean & SD & \\
\hline Protein & $12 \cdot 9$ & $2 \cdot 4$ & $14 \cdot 8$ & 0.8 & 0.030 \\
\hline Total fat & $38 \cdot 9$ & $8 \cdot 1$ & $48 \cdot 9$ & 8.1 & 0.009 \\
\hline SFA & $6 \cdot 2$ & $0 \cdot 8$ & $13 \cdot 4$ & 1.3 & 0.005 \\
\hline MUFA & $23 \cdot 1$ & $7 \cdot 1$ & $23 \cdot 9$ & 6.6 & 0.610 \\
\hline PUFA & $6 \cdot 1$ & $1 \cdot 1$ & $5 \cdot 6$ & $1 \cdot 9$ & 0.074 \\
\hline Trans-fatty acids & $0 \cdot 10$ & 0.20 & $0 \cdot 60$ & 0.20 & 0.005 \\
\hline$n-6$ fatty acids & $4 \cdot 0$ & $1 \cdot 3$ & $4 \cdot 9$ & $1 \cdot 8$ & 0.284 \\
\hline$n-3$ fatty acids & 0.4 & $0 \cdot 2$ & 0.4 & $0 \cdot 2$ & 0.754 \\
\hline Total carbohydrates & $48 \cdot 7$ & 8.5 & $36 \cdot 1$ & $9 \cdot 2$ & 0.005 \\
\hline
\end{tabular}

*Levels of significance were assessed with the use of the Wilcoxon signed ranks test.

of people living in monasteries and free-living individuals who perform fasts, in comparison with matched controls who never perform fasts ${ }^{(9)}$. Fasters were generally reported to have lower intakes of dietary cholesterol, total and saturated fat, protein and $\mathrm{Ca}$, and higher intakes of dietary fibre, folate, Fe and carbohydrates, during fasting as compared with non-fasting periods ${ }^{(9)}$. In this earlier study, fish/seafood consumption also appeared to be 
Table 4 Estimation of daily intake of selected foods $(\mathrm{g} / \mathrm{d})$ in Greek Orthodox Christian monks during a fasting and a non-fasting week, based on $7 d$ weighed food records

\begin{tabular}{|c|c|c|c|c|c|}
\hline \multirow[b]{2}{*}{ Food group } & \multicolumn{2}{|c|}{ Fasting week ( $n$ 10) } & \multicolumn{2}{|c|}{ Non-fasting week ( $n$ 10) } & \multirow[b]{2}{*}{$P$} \\
\hline & Mean & SD & Mean & SD & \\
\hline Bread & $140 \cdot 0$ & $108 \cdot 0$ & $79 \cdot 1$ & $67 \cdot 7$ & $0.074^{*}$ \\
\hline Cereals & $127 \cdot 0$ & $76 \cdot 1$ & $113 \cdot 0$ & $61 \cdot 0$ & $0.445^{\star}$ \\
\hline Potatoes & $66 \cdot 8$ & $54 \cdot 3$ & $102 \cdot 0$ & $45 \cdot 5$ & $0 \cdot 169^{*}$ \\
\hline Milk and yoghurt & 0 & 0 & $39 \cdot 5$ & $77 \cdot 3$ & $0.027^{\star}$ \\
\hline Cheese & 0 & 0 & $52 \cdot 7$ & $29 \cdot 8$ & $0.008^{*}$ \\
\hline Eggs & 0 & 0 & $25 \cdot 5$ & $17 \cdot 7$ & $0.012^{*}$ \\
\hline Meat & 0 & 0 & $146 \cdot 0$ & $70 \cdot 4$ & $0.008^{*}$ \\
\hline Fish and seafood & $87 \cdot 1$ & $35 \cdot 6$ & $25 \cdot 0$ & $31 \cdot 6$ & $0.009^{*}$ \\
\hline Legumes & $63 \cdot 5$ & $34 \cdot 5$ & $13 \cdot 3$ & $12 \cdot 2$ & $0.005^{\star}$ \\
\hline Snails & $23 \cdot 8$ & $40 \cdot 4$ & $5 \cdot 86$ & $18 \cdot \overline{5}$ & $0 \cdot 123^{*}$ \\
\hline Fruits and nuts & $144 \cdot 0$ & $83 \cdot 0$ & $114 \cdot 0$ & $95 \cdot 5$ & $0.446 \dagger$ \\
\hline Vegetables & $237 \cdot 0$ & $101 \cdot 0$ & $163 \cdot 0$ & $75 \cdot 9$ & $0.074^{*}$ \\
\hline Alcoholic drinks & $54 \cdot 0$ & 83.5 & $62 \cdot 4$ & 72.5 & $0.314^{*}$ \\
\hline Fats and oils & $62 \cdot 4$ & $28 \cdot 7$ & 64.9 & $12 \cdot 3$ & $0.746 t$ \\
\hline Sugar/sugar products & $14 \cdot 8$ & $6 \cdot 8$ & $16 \cdot 4$ & $14 \cdot 9$ & $0.799^{\star}$ \\
\hline Pastries & $63 \cdot 3$ & $66 \cdot 9$ & $74 \cdot 1$ & $65 \cdot 4$ & $0.646^{*}$ \\
\hline
\end{tabular}

*Levels of significance were assessed with the use of the Wilcoxon signed ranks test.

thevels of significance were assessed with the use of the paired-samples $t$ test.

higher whereas, in contrast to the present study, legume intake was lower when participants fasted. Meat consumption during non-fasting periods was similar to the intake reported during the non-fasting week in the present study ${ }^{(9)}$

A model of the Greek Orthodox fasting rituals was also established in another study, which assessed the nutrient composition of this eating pattern by chemically analysing the weekly food and nutrient intake of a strict adherent to the Church's recommendations ${ }^{(11)}$. Similar to our findings, that study demonstrated higher intakes of dietary fibre and antioxidant vitamins and lower intakes of saturated fat and dietary cholesterol compared with adults and adolescents of the same region.

The present study is, to our knowledge, the first to specifically evaluate the intake of $\mathrm{Ca}$ in the Mediterranean diet and, in particular, its intake during a dietary fasting period associated with a religious practice. Our expectation that $\mathrm{Ca}$ intakes would be lower during the fasting week, compared with the non-fasting week, was confirmed. This is in accordance with earlier literature ${ }^{(9,11)}$ and most probably reflects the restriction of dairy products during Greek Orthodox fasting periods. A finding of concern is that mean Ca intake was low during both assessment weeks. Although there are wide variations in the estimates of daily $\mathrm{Ca}$ requirements and recommended levels made by different expert authorities, depending among other factors on age, food patterns and physical activity levels, this agrees with evidence that $\mathrm{Ca}$ intakes are below the recommended levels for many population groups $^{(16,17,20)}$. In the past, calculation of $\mathrm{Ca}$ intake has been reported to be underestimated due to underreporting of food intakes. In addition, dietary supplements, drinking water and Ca-fortified foods might well contribute to total $\mathrm{Ca}$ intake ${ }^{(17)}$. However, under-reporting of food intake, which might have led to low reported $\mathrm{Ca}$ intakes, is unlikely to have occurred in the present study owing to the dietary assessment method used (weighed food record). Furthermore, participants in the present study did not take dietary supplements and did not report consuming any fortified foods, so the contribution of these two factors in their $\mathrm{Ca}$ intake is probably zero. Nevertheless, short-term dietary $\mathrm{Ca}$ insufficiencies have not been reported to be detrimental to health ${ }^{(30)}$. In addition, Ca bioavailability is an important factor that should always be studied along with the Ca content of foods ${ }^{(20)}$.

The study by Sarri et al. reported that habitual fasters displayed decreased blood lipid levels and body weight during fasting periods compared with non-fasting periods $^{(8)}$, in agreement with our results. In the present study, body weight and BMI did not reach statistical significance, however, probably due to the small sample size. Decreased HDL-C levels have previously been associated with low-fat and vegetarian diets ${ }^{(31)}$, which might explain the lower levels of this lipid marker during the fasting week in this population. In addition, systolic blood pressure appeared to be significantly higher at the end of the fasting week. This increased level of systolic blood pressure was observed despite the restriction of animal foods and the estimated lower mean intake of $\mathrm{Na}$ and higher mean intake of $\mathrm{K}$ during the fasting period (Tables 4 and 2). This was perhaps a result of lower $\mathrm{Ca}$ intakes during that week, since dietary $\mathrm{Ca}$ has been beneficially implicated in the regulation of blood pressure $^{(15)}$. Another possible explanation could be that for the taste of meals to be improved during the fasting week, salt added to foods during cooking or at the table increased. Added salt intake was not, however, assessed in this study. Diastolic blood pressure was not changed 
between the two assessment weeks, which agrees with the earlier study reporting results on these measurements ${ }^{(8)}$.

A further indication of the healthy dietary habits associated with the Greek Orthodox Church's fasting rituals is the increased mean daily fruit and vegetable intake observed during the fasting week. We contend that seasonal variation would not affect the intake of this food group, since recording of dietary data took place during spring and summer months when seasonal, fresh fruits and vegetables are abundant in Greece. It seems more probable that the allowed consumption of animal products during the non-fasting week led to substitution of some of the fruits and vegetables, usually consumed during fasting, with animal-origin foods. The lack of statistical significance concerning the intake of fruits and vegetables in the two assessment weeks, in contrast to the study by Sarri et $a l .{ }^{(9)}$, might have been the result of the small sample size.

The healthier lifestyle of strict Orthodox Christian fasters has also been reported by Sarri et al. ${ }^{(9)}$ and was confirmed in the present study, where none of the participants smoked and their alcohol intake averaged approximately one serving of alcoholic drinks per day. In addition, fasting is proposed to 'allow the body to rest and recuperate', since energy intake and the consumption of energy-dense foods decrease during fasting periods ${ }^{(7)}$. Although it did not reach statistical significance, mean daily energy intake in the present study was lower by about $840 \mathrm{~kJ}(200 \mathrm{kcal})$ during the fasting week compared with the non-fasting week. This healthier lifestyle might add to the favourable lipid profile of this population.

Although the results from the present study are adding to earlier research on Greek Orthodox Church fasting recommendations, our findings cannot be generalised to all Orthodox Christians since the sample size was small, mainly due to the limited number of monks living in Crete and the increased number of measurements involved. In addition, some selection bias might have occurred since participants volunteered to take part in the study. Selfselection of participants, however, has been shown to result in the provision of more accurate responses in food consumption surveys compared with non-volunteers ${ }^{(32)}$. Nevertheless, these findings give a good indication of the health benefits of the fasting rituals of the traditional Mediterranean diet of Crete, as indicated by the favourable blood lipid profile of this population and the generally healthier eating habits during fasting. A study we are currently undertaking, involving a bigger sample of nuns and a sex- and age-matched control group of freeliving individuals, will ideally shed more light into the potential benefits of Greek Orthodox Christian fasting recommendations.

In recent years, a number of researchers have used the recommendations of the traditional Mediterranean diet of Crete as the nutritional basis of secondary ${ }^{(33,34)}$ and primary $^{(35)}$ nutrition interventions and shown that this eating pattern can be successfully adopted by patients who are motivated to change their diet, as well as healthy volunteers. Apart from good dietary acceptability, these earlier studies have reported favourable effects on several biomarkers associated with health. The present study confirms that this traditional eating pattern, which incorporates a kind of periodic vegetarianism, as recommended by the Greek Orthodox Church fasting rituals, could offer cardioprotective benefits, as reflected in the favourable blood lipid profiles observed in this sample of habitual fasters. Although long-term effects of these fasting recommendations are yet to be investigated by a cohort study and such a diet should be carefully planned and balanced to avoid the insufficient intake of micronutrients such as $\mathrm{Ca}$, its potential importance should be emphasised in nutrition education programmes promoting this Mediterranean eating pattern.

\section{Acknowledgements}

We confirm that we do not have any financial interests or conflicts of interest that may interfere with the potential publication of this work. The study was funded by an internal grant of the University of Crete. A.P. analysed the data and co-authored the paper. C.V. Co-authored the paper. C.H. co-authored the paper. A.K. designed and conducted the study and co-authored the paper. The authors would like to thank the monasteries involved in the study for their kind cooperation, the dietitians of the team for their valuable help with data entry, and Dr Katerina Sarri for her advice.

\section{References}

1. Nestle M (1995) Mediterranean diets: historical and research overview. Am J Clin Nutr 61, 1313S-1320S.

2. Keys A (1970) Coronary heart disease in seven countries. Circulation 41, 1-211.

3. Kromhout D, Keys A, Aravanis C et al. (1989) Food consumption patterns in the 1960s in seven countries. Am J Clin Nutr 49, 889-894.

4. Helsing E (1995) Traditional diets and disease patterns of the Mediterranean, circa 1960. Am J Clin Nutr 61, 1329S-1337S.

5. Kafatos A, Kouroumalis I, Vlachonikolis I, Theodorou C \& Labadarios D (1991) Coronary-heart-disease risk-factor status of the Cretan urban population in the 1980s. Am J Clin Nutr 54, 591-598.

6. Hakim I (1998) Mediterranean diets and cancer prevention. Arch Intern Med 158, 1169-1170.

7. Cannon G (2004) Out of the Christmas box. Public Health Nutr 7, 987-990.

8. Sarri KO, Tzanakis NE, Linardakis MK, Mamalakis GD \& Kafatos AG (2003) Effects of Greek orthodox Christian church fasting on serum lipids and obesity. BMC Public Health 3, 16.

9. Sarri KO, Linardakis MK, Bervanaki FN, Tzanakis NE \& Kafatos AG (2004) Greek Orthodox fasting rituals: a hidden characteristic of the Mediterranean diet of Crete. Br J Nutr 92, 277-284. 
10. Chliaoutakis JE, Drakou I, Gnardellis C, Galariotou S, Carra H \& Chliaoutaki M (2002) Greek Christian orthodox ecclesiastical lifestyle: could it become a pattern of health-related behavior? Prev Med 34, 428-435.

11. Kafatos A, Verhagen H, Moschandreas J, Apostolaki I \& Van Westerop JJM (2000) Mediterranean diet of Crete: foods and nutrient content. J Am Diet Assoc 100, 1487-1493.

12. Galli C \& Marangoni F (2006) N-3 fatty acids in the Mediterranean diet. Prostaglandins Leukot Essent Fatty Acids 75, 129-133.

13. Sabaté J (2004) Religion, diet and research. Br J Nutr 92 , 199-201.

14. Trichopoulou A, Kouris-Blazos A, Wahlqvist ML, Gnardellis C, Lagiou P, Polychronopoulos E, Vassilakou T, Lipworth L \& Trichopoulos D (1995) Diet and overall survival in elderly people. BMJ 311, 1457-1460.

15. Miller GD, Jarvis JK \& McBean LD (2001) The importance of meeting calcium needs with foods. J Am Coll Nutr 20, 168S-185S.

16. Fishbein L (2004) Multiple sources of dietary calcium some aspects of its essentiality. Regul Toxicol Pharmacol 39, 67-80.

17. Cashman KD (2002) Calcium intake, calcium bioavailability and bone health. BrJ Nutr 87, S169-S177.

18. Matkovic V (1992) Calcium and peak bone mass. J Intern Med 231, 151-160.

19. Miller DD (1989) Calcium in the diet: food sources, recommended intakes and nutritional bioavailability. $A d v$ Food Nutr Res 33, 103-156.

20. Weaver CM, Proulx WR \& Heaney R (1999) Choices for achieving adequate dietary calcium with a vegetarian diet. Am J Clin Nutr 70, 543S-548S.

21. New SA (2004) Do vegetarians have a normal bone mass? Osteoporos Int 15, 679-688.

22. Kaur N \& Gupta AK (2002) Applications of inulin and oligofructose in health and nutrition. $J$ Biosci 27, 703-714.

23. Heaney RP \& Weaver CM (1990) Calcium absorption from kale. Am J Clin Nutr 51, 656-657.

24. Warnick R, Benderson J \& Albers JJ (1982) Dextran sulphate $-\mathrm{Mg}^{2+}$ precipitation procedure for quantitation of high-density-lipoprotein cholesterol. Clin Chem 28, 1379-1384.

25. Friedewald WT, Levy RI \& Fredrickson DS (1972) Estimation of the concentration of low density lipoprotein cholesterol in plasma without the use of the preparative ultracentrifuge. Clin Chem 18, 499-502.

26. Moschandreas J \& Kafatos A (1999) Food and nutrient intakes of Greek (Cretan) adults. Recent data for food-based dietary guidelines in Greece. Br J Nutr 81, S71-S76.

27. Kinosian B, Glick H \& Garland G (1994) Cholesterol and coronary heart disease: predicting risks by levels and ratios. Ann Intern Med 121, 641-647.

28. Williams C (1995) Healthy eating: clarifying advice about fruit and vegetables. BMJ 310, 1453-1455.

29. World Health Organization (2003) Diet, Nutrition and the Prevention of Chronic Diseases. Joint WHO/FAO Expert Consultation. WHO Technical Report Series no. 916. Geneva: WHO.

30. O'Brien KO, Abrams SA, Liang LK, Ellis KJ \& Gagel RF (1996) Increased efficiency of calcium absorption during short periods of inadequate calcium intake in girls. $A m J$ Clin Nutr 64, 579-583.

31. Masarei JR (1984) Vegetarian diets, lipids and cardiovascular risk. Aust N Z J Med 14, 400-404.

32. Cade J, Thompson R, Burley V \& Warm D (2002) Development, validation and utilisation of food-frequency questionnaires - a review. Public Health Nutr 5, 567-587.

33. Renaud S, de Lorgeril M, Delaye J, Guidollet J, Jacquard F, Mamelle N, Martin JL, Monjaud I, Salen P \& Toubol P (1995) Cretan Mediterranean diet for prevention of coronary heart disease. Am J Clin Nutr 61, 1360S-1367S.

34. de Lorgeril M, Salen P, Martin JL, Monjaud I, Boucher P \& Mamelle N (1998) Mediterranean dietary pattern in a randomized trial: prolonged survival and possible reduced cancer rate. Arch Intern Med 158, 1181-1187.

35. Papadaki A \& Scott JA (2005) The Mediterranean Eating in Scotland Experience project: evaluation of an Internetbased intervention promoting the Mediterranean diet. Br J Nutr 94, 290-298. 